\title{
CDISC SDTM Action Taken with Study Treatment Terminology
}

National Cancer Institute

\section{Source}

National Cancer Institute. CDISC SDTM Action Taken with Study Treatment

Terminology. NCI Thesaurus. Code C66767.

Terminology associated with the action taken with study treatment codelist of the Clinical

Data Interchange Standards Consortium (CDISC) Study Data Tabulation Model (SDT M). 